\title{
Effects of global changes on the climatic niche of the tick Ixodes ricinus inferred by species distribution modelling
}

Daniele Porretta', Valentina Mastrantonio ${ }^{1}$, Sara Amendolia', Stefano Gaiarsa², Sara Epis ${ }^{2,3}$, Claudio Genchi², Claudio Bandi ${ }^{2}$, Domenico Otranto ${ }^{4}$ and Sandra Urbanelli ${ }^{1 *}$

\begin{abstract}
Background: Global climate change can seriously impact on the epidemiological dynamics of vector-borne diseases. In this study we investigated how future climatic changes could affect the climatic niche of Ixodes ricinus (Acari, Ixodida), among the most important vectors of pathogens of medical and veterinary concern in Europe.

Methods: Species Distribution Modelling (SDM) was used to reconstruct the climatic niche of I. ricinus, and to project it into the future conditions for 2050 and 2080, under two scenarios: a continuous human demographic growth and a severe increase of gas emissions (scenario A2), and a scenario that proposes lower human demographic growth than A2, and a more sustainable gas emissions (scenario B2). Models were reconstructed using the algorithm of "maximum entropy", as implemented in the software MAXENT 3.3.3e; 4,544 occurrence points and 15 bioclimatic variables were used.

Results: In both scenarios an increase of climatic niche of about two times greater than the current area was predicted as well as a higher climatic suitability under the scenario B2 than A2. Such an increase occurred both in a latitudinal and longitudinal way, including northern Eurasian regions (e.g. Sweden and Russia), that were previously unsuitable for the species.

Conclusions: Our models are congruent with the predictions of range expansion already observed in I. ricinus at a regional scale and provide a qualitative and quantitative assessment of the future climatically suitable areas for I. ricinus at a continental scale. Although the use of SDM at a higher resolution should be integrated by a more refined analysis of further abiotic and biotic data, the results presented here suggest that under future climatic scenarios most of the current distribution area of I. ricinus could remain suitable and significantly increase at a continental geographic scale. Therefore disease outbreaks of pathogens transmitted by this tick species could emerge in previous non-endemic geographic areas. Further studies will implement and refine present data toward a better understanding of the risk represented by I. ricinus to human health.
\end{abstract}

Keywords: Climatic changes, Future climatic niche, Species distribution modeling, Tick, Vector-borne disease, Lyme disease, Babesiosis, Anaplasmosis, Erlichiosis and tick-borne encephalitis

\footnotetext{
* Correspondence: sandra.urbanelli@uniroma1.it

'Department of Environmental Biology, University of Rome "La Sapienza",

Via dei Sardi 70, 00185 Rome, Italy

Full list of author information is available at the end of the article
} 


\section{Background}

Global climate change can seriously impact on the epidemiological dynamics of vector-borne diseases [1-5]. However, because of the influence of several biotic and abiotic factors on hosts, arthropods and pathogens they vector, future spatial and temporal distribution of vectorborne diseases is still difficult to predict $[4,6]$. Under the above circumstances, predicting how climatic changes will affect geographic distribution of the vector is an obligate step. Indeed, vectors play a key role in infectious disease areas where they may transmit pathogens to a variety of animal hosts, often representing the bridge between zoonotic reservoirs and humans $[3,7,8]$. Likewise, since pathogens may disperse through arthropods into previously non-endemic areas, climate-induced changes in vector distribution ultimately affect the epidemiology of vectorborne diseases $[3,9]$. In addition, a distributional shift of vectors may also lead to spatial overlap of different vector species [10], thus changing the impact of pathogen transmission, interfering with their epidemic cycles [4] or as a consequence of vector interspecific competition [11-13].

In the last few years, Species Distribution Modelling (SDM) has greatly contributed to understanding the effect of climatic changes on vector distribution, combining known occurrence points of a species with a set of climatic variables $[14,15]$. Indeed, such an approach allows developing the potential geographic distribution under current and future climatic conditions [16-19]. SDM has been used in several studies on arthropod vectors [20-25], allowing to infer future range expansion, such as in the case of sand fly species Lutzomyia anthophora and L. diabolica in North America [22], or a potential distributional shift and/or a reduction of geographic range, as suggested for the malaria vectors in Africa [21].

In this study we investigated how future climatic changes could affect the climatic niche of the tick Ixodes ricinus (Acari, Ixodidae). This species is regarded as the most important vector occurring in Eurasian regions since it is a multi-competent vector of bacteria (i.e. Borrelia burgdorferi s.l., Babesia spp., Anaplasma and Erlichia spp.) and viruses (i.e. Flavivirus spp.), to humans and animals [26-30]. The above tick species is regarded as a major vector responsible for many zoonotic diseases, such as Lyme disease, babesiosis, anaplasmosis, erlichiosis and Tick-Borne Encephalitis (TBE) [31]. Ixodes ricinus has been recorded in Europe, Russia, up to the Caspian Sea on the east, and North Africa [32]. Along the western boundary of Russia and the neighboring countries, its range overlaps with the range of I. persulcatus tick, distributed in Eastern Europe and across Asia [30,33,34]. Recently, a latitudinal and altitudinal shift has been reported in $I$. ricinus distribution in European regions, and temperature rise was suggested to be among the factors responsible for this phenomenon [35-40]. In spite of the epidemiological implications that vector distribution changes might have on vectored pathogens, no studies have investigated the impact of future climatic changes on the geographic distribution of this tick species at a continental geographic scale.

By using SDM we aimed to reconstruct the climatic niche of $I$. ricinus and projected it into the future conditions for 2050 and 2080, under two possible scenarios: i) a continuous human demographic growth and a severe increase of gas emissions (A2 scenario), ii) a lower human demographic growth than A2, and a more sustainable gas emissions (scenario B2) [41].

\section{Methods}

To reconstruct the current and future climatic niche of I. ricinus, the algorithm of "maximum entropy" has been used, as implemented in the software MAXENT 3.3.3e. This technique, using presence-only points in conjunction with environmental variables, estimates the potential distribution of the species finding the probability distribution that approximates the distribution of maximum entropy [42]. This approach is largely used to reconstruct SDM because its performances are highly competitive with the other modeling methods. Indeed it showed the better calibration when compared to 16 other algorithms, including several traditional tools using presence-absence data, such as general linear models (GLM) and general additive models (GAM) [18,43-46]. To model the current and future climatic niche of I. ricinus, we used 4,544 occurrence points (Figure 1) obtained from the digital dataset available at https://sites.google.com/site/palticks/home/download [47]. The dataset includes occurrence points obtained by a systematic search of the published, peer-reviewed literature since, approximately, 1970 to 2010; records of ticks available in some curated collections were also included. It covers most of the $I$. ricinus range and does not include records considered as potentially incorrect, based on the known distribution of I. ricinus [47]. Environmental data were downloaded from WorldClim database (www.worldclim.org) with a resolution of 2.5 arc-minutes $(\sim 5 \mathrm{~km})$. Nineteen bioclimatic variables derived from monthly temperature and rainfall values were downloaded, that represent annual trends, seasonality and extreme or limiting environmental factors. The runs have been made using $75 \%$ of the occurrence points to construct the model (training data) and the remaining $25 \%$ to test it. The default parameters of MAXENT have been used with the exception of the Regularization parameter $\beta$. This parameter acts as a multiplier for the default values and it regulates the smoothness and regularity of the model $[44,48]$. Recently, Warren \& Seifert [48] have highlighted the importance to test different values of this parameter to improve the MAXENT's performance. We developed ten models using different values of $\beta(1,3,5,7,9,11,13,15$, 


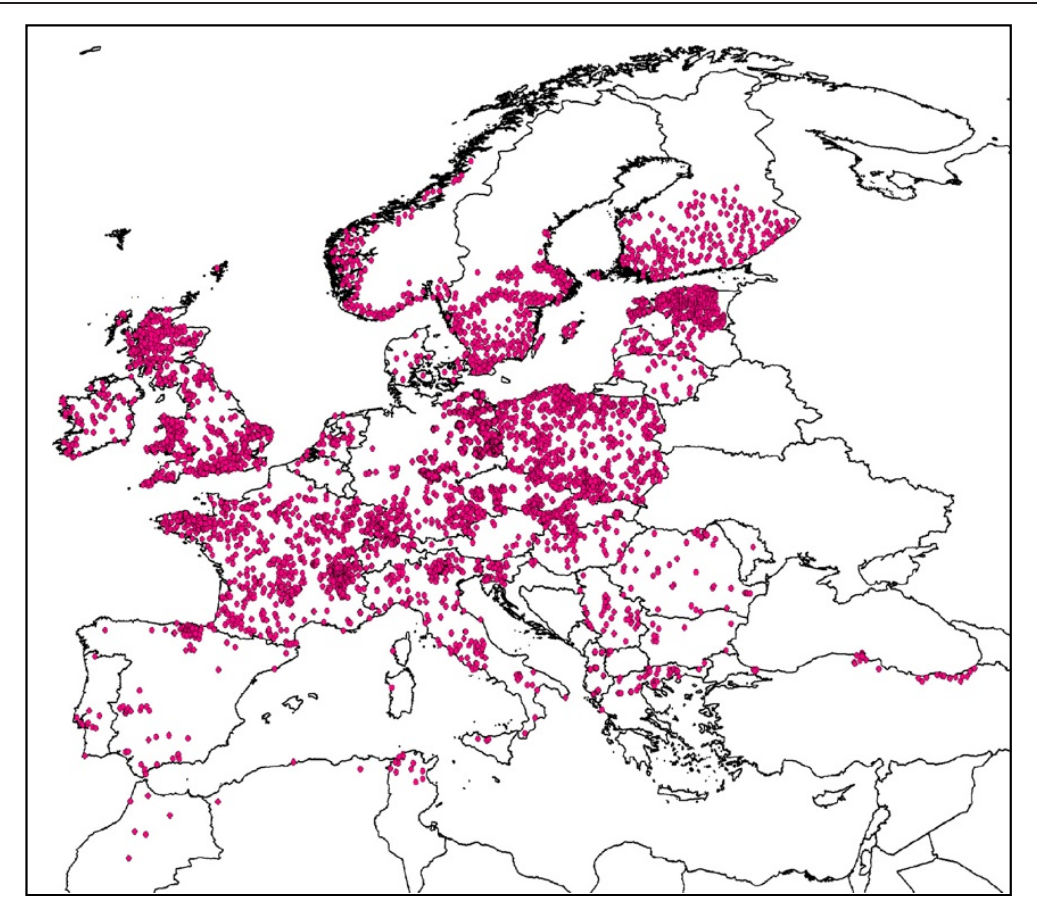

Figure 1 Occurrence points. Map shows the 4,544 records of I. ricinus used to develop the Species Distribution Modelling.

17 and 19) and then we chose the model that outperformed all the others using the sample sized corrected Akaike Information Criterion $\left(\mathrm{AIC}_{\mathrm{c}}\right)$ score, as implemented in the software ENMTOOLS. The model built with the value of $\beta$ equal to 1 gained the lowest score for the $\mathrm{AIC}_{\mathrm{c}}$, thus outperforming all the remaining nine models tested, therefore it has been used to reconstruct the final models. To evaluate the accuracy of the developed models we used the area under the curve (AUC) of the receiver operating characteristic (ROC) as suggested by Peterson et al. [49]. Explorative analyses have been done using all 19 variables, then the environmental variables outside the range present in the training data have been excluded. The final models have been reconstructed using 15 variables (Additional file 1). Ten replicates were run using the cross-validation form of replication. This approach randomly split the data into equal-size groups ("folds") and creates models leaving out each fold in turn and using them for evaluation [50]. The model developed for the present-day conditions has been projected onto the future climatic conditions. Two scenarios proposed by the Special Report of Emission Scenarios (SRES) of the Inter-governmental Panel on Climate Change (IPCC) [51], have been considered, namely: scenario A2 (that proposes a continuous human demographic growth and a severe increase of gas emissions) and scenario B2 (that proposes lower human demographic growth than A2, and a more sustainable gas emissions) $[17,41]$. Potential climatic niche under these scenarios has been predicted for 2050 and 2080 using the Canadian
Center for Climate Modeling and Analysis CCCAMCGCM3.1-T47 model [52].

All SDM predictions were visualized in Quantum-GIS 1.8.0 (http://download.qgis.org). To estimate the future increase of the niche area respect to current model, presence/absence maps using the minimum training presence threshold were constructed [53]. Then future increase of the niche area respect to current model was calculated using the software ImageJ (http://rsb.info.nih.gov/ij/).

\section{Results}

The averaged climatic niche of the species for current conditions is shown in Figure 2a. The averaged value of AUC for this model was $0.860( \pm 0.004)$, indicating an optimal performance of the models. Among the 15 variables used BIO6 (Min Temperature in the coldest period) and BIO17 (Precipitation of the driest quarter) give the highest percent contribution to construct the model (Additional file 1), according to the biology of I. ricinus, that lives in biotopes that offer moderate temperatures and high relative humidity [54]. The climatically suitable area predicted by our model under current conditions encompasses the known geographic distribution of $I$. ricinus and that previously inferred for this species using both climatic features and vegetation index [55], supporting the validity of our reconstruction.

In Figure 2b-e the models predicted under future climatic conditions are shown. In both scenarios an increase of a climatically suitable area of about two times greater than 


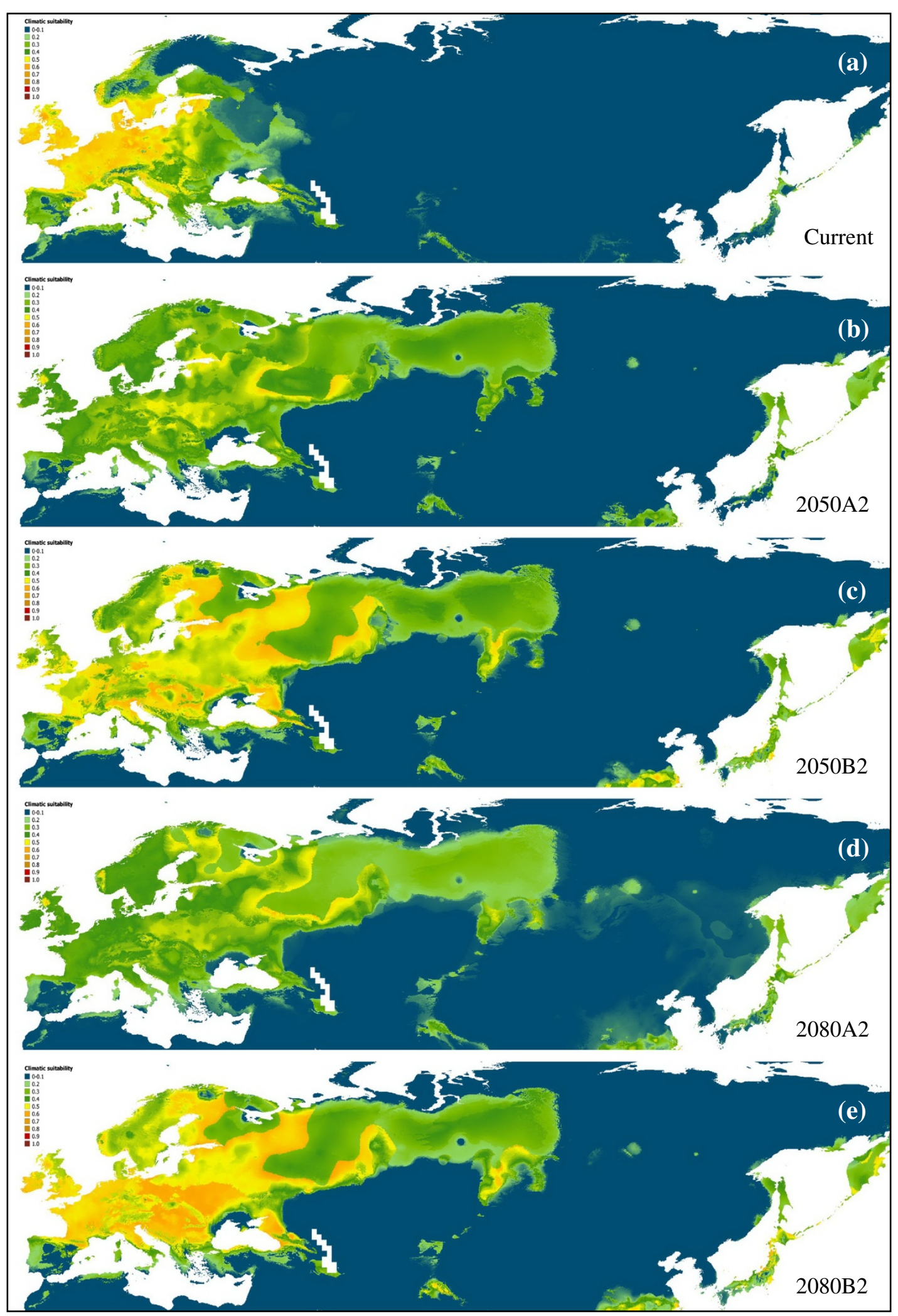

Figure 2 Geographic distribution predicted by species distribution modelling for Ixodes ricinus. (a) Current conditions; (b-c) 2050, scenario A2 and B2, respectively; (d-e) 2080, scenario A2 and B2, respectively. 
the current area was predicted (Additional file 2). Such an increase occurred both in a latitudinal and longitudinal way, including northern Eurasian regions (e.g. Sweden and Russia), that were previously unsuitable for the species. Notably, climatically suitable conditions appeared also in the easternmost Asian region, such as Central China, South Korea, Japan and Kamchatka Peninsula. While the two scenarios showed no difference about the extension of the predicted suitable area, they instead showed some difference in its climatic suitability. Indeed, under the scenario B2 most of the predicted area showed a higher climatic suitability than A2 in both 2050 and 2080. Furthermore, under the scenario B2 an increase of climatic suitability for I. ricinus has been predicted between 2050 and 2080 in several areas (i.e. Ireland and Eastern Europe) (Figure 2c,e).

\section{Discussion}

The increase in temperature, which has been predicted to occur in the future years [41], could drastically affect the ecology and geographic distribution of $I$. ricinus in Eurasian regions. Climatic changes have been shown to affect seasonal activity and feeding behavior of I. ricinus, at different life stages $[3,32,40]$. Furthermore, because of the I. ricnus vulnerability to drought [54], global warming may affect negatively the species in southernmost part of its range of distribution. On the other hand, higher temperature could lead to milder winter and extended spring and autumn seasons than those actually characterizing northern regions, making these areas climatically suitable for the species. Evidence that this latter phenomenon is in progress in Europe has been already recorded for I. ricinus, in which an expansion of the northern distribution limits in Sweden and Norway has been reported since the 1980s [35,38-40,56]. Likewise, a shift of the limit to higher altitudes northward in Czech Republic and Switzerland respectively, has been shown $[36,37]$. Our results by using SDM are congruent with the predictions of range expansion and provide a qualitative and quantitative assessment of the future areas climatically suitable for I. ricinus at a continental scale.

While interpreting inferred expansion of climatic niche in the context of possible changes in geographic distribution of I. ricinus [15-18] the following two issues should be considered. First, the climatic features are only one of the ecological features that affect the geographic distribution of tick species $[57,58]$. However, I. ricinus, as all other ixodid ticks, spend most of their life off the host, so that climate is an essential determinant of their occurrence $[59,60]$. At a smaller geographic scale, other abiotic factors should be considered to assess the effective occurrence of I. ricinus, such as landscape physical features, or landscape use [15] and biotic factors (competition, hosts abundance etc.) $[15,61,62]$. The integration of these factors could show discontinuity in areas that our model predicted as large continuous areas of climate suitability. With respect to biotic factors, the hosts are key components for the ecological niche of ticks $[7,63,64]$. Ixodes ricinus is able to exploit a large variety of terrestrial vertebrates $[7,63-65]$, so that host occurrence should not be a limiting factor to their persistence under climatic change scenarios [66]. Its wide ecological plasticity with respect to host choice, for example, was a key factor in allowing I. ricinus to survive during the last glacial phases without significant range reduction across the European continent [67].

Secondly, it should be considered that in order to have an effective range expansion, the new climatically suitable areas should be reached by the species. Host movements largely determine tick dispersal during infestation [65,68-72]. Among the several hosts exploited by $I$. ricinus, some of them, such as birds and cervids, are characterized by high dispersal ability. Host mediated dispersal of ticks also across long distances and more distant geographic areas have been demonstrated in several studies both for I. ricinus [72-74] and for other tick species [40,67,75-77]. Following the above considerations, although the use of SDM models at a higher resolution should be integrated by a more refined analysis of further abiotic and biotic data, the general significance of results presented here suggest that under future climatic scenarios, most of the current distribution area of I. ricinus could remain suitable and significantly increase at a continental geographic scale.

Our results suggest also that the more favourable climatic conditions for $I$. ricinus will occur under the scenario B2 (i.e., lower human demographic growth, and a more sustainable gas emissions than A2). Interestingly, reduced demographic growth and gas emissions are objectives of several international policies [78]. In this context it is further advisable to investigate the factors that could affect the epidemiological dynamics in which this tick is involved. For example, future inferred expansion eastward of the climatic niche of I. ricinus could increase the overlapping areas with the Eurasian tick I. persulcatus [79], increasing or decreasing pathogen transmission due to vector interspecific competition [11-13], or to interferences among pathogen epidemic cycles [4]. This may be the case for Borrelia spp. in which a relationship has been established between bacterial complexes and tick species. Indeed, while the Eurasian type of $B$. garinii and $B$. afzelii are carried by both $I$. ricinus and I. persulcatus in North Asian regions, B. burgdorferi s.s. seems to be vectored exclusively by $I$. ricinus, and the Asian type of B. garinii by I. persulcatus [80]. The expansion of the areas of co-presence of the two tick species could enhance the diffusion of the types for which both of them are competent. 


\section{Conclusions}

In the epidemiological systems involving $I$. ricinus as a vector, climatic changes have been shown to have several effects. First, the seasonal activity of ticks could undergo some changes $[40,81]$. Indeed, previous studies conducted on $I$. ricinus showed that this species could prolong its questing season, usually spanning from March to November, until January as a response of milder winters due to the temperature increase [3,81-84]. As a consequence, more abundant populations of ticks could survive the winter, thus a higher probability of tick bites, and in turn of disease transmission, could be expected [82]. Second, different life stages could become active and search for a host simultaneously $[32,40]$. Larvae and nymphs could parasitize the same host individual at the same time, favoring the trans-stadial transmission of pathogens by co-feeding and enhancing the efficiency of disease transmission $[40,85]$. In addition, our results suggest a potential significant increase of climatic niche of I. ricinus in the future years under both scenarios. Therefore disease outbreaks of pathogens transmitted by this tick species could emerge in previous non-endemic geographic areas. Further studies will implement and refine present data toward a better understanding of the risk represented by $I$. ricinus for human health.

\section{Additional files}

Additional file 1: List of bioclimatic variables used to develop the Species Distribution Models and variable percent contribution to construct the models.

Additional file 2: Increase of geographic distribution of Ixodes ricinus, predicted by species distribution modelling. The values under Current, 2050 and 2080 (A2 and B2 scenarios) columns represent the areas in square $\mathrm{km}$. The values in the Ratio column represent the increase of area as ratio between future and current conditions.

\section{Competing interests}

The authors declare that they have no competing interests.

\section{Authors' contributions}

DP, VM, SA SU, conceived and designed the study. DP, VM, SA drafted the manuscript. VM, SA analyzed the data. SG, SE, CG, CB, DO critically revised the manuscript. All authors read and approved the final manuscript.

\section{Acknowledgment}

We thank Alessandra Spanò for technical assistance; the editors and four anonymous reviewers for their comments and suggestions. The work was funded through grants from the Ministero dell'Istruzione, dell'Università e della Ricerca (MIUR)

\section{Author details}

"Department of Environmental Biology, University of Rome "La Sapienza", Via dei Sardi 70, 00185 Rome, Italy. '2Department of Veterinary Science and Public Health, University of Milan, Milan, Italy. ${ }^{3}$ School of Bioscience and Biotechnology, University of Camerino, Camerino, Italy. ${ }^{4}$ Department of Veterinary Medicine, University of Bari, Bari, Italy.

Received: 24 July 2013 Accepted: 12 September 2013

Published: 19 September 2013
References

1. Githeko AK, Lindsay SW, Confalonieri UE, Patz JA: Climate change and vector-borne diseases: a regional analysis. Bull World Health Organ 2000, 78:1136-1147.

2. Patz JA, Olson SH: Climate change and health: global to local influences on disease risk. Ann Trop Med Parasit 2006, 100:535-549.

3. Gage KL, Burkot TR, Eisen RJ, Hayes EB: Climate and vector borne disease. Am J Prev Med 2008, 35:436-450.

4. Tabachnick WJ: Challenges in predicting climate and environmental effects on vector-borne disease episystems in a changing world. $J$ Exp Biol 2009, 213:946-954

5. Mirski T, Bartoszcze M, Bielawska-Dròzd A: Impact of climate change on infectious diseases. Pol J Environ Stud 2012, 3:525-532.

6. Mills JN, Gage KL, Khan AS: Potential influence of climate change on vector-borne and zoonotic diseases: a review and proposed research plan. Environ Health Perspect 2010, 118:1507-1514.

7. Sonenshine DE: The biology of tick vectors of humans disease. In Tick-borne diseases of humans. Edited by Goodman JL, Dennis DT, Sonenshine DE. Washington: ASM Press; 2003:12-31.

8. Eisen RJ, Eisen L: Spatial modeling of human risk of exposure to vectorborne pathogens based on epidemiological versus arthropod vector data. J Med Entomol 2008, 45:181-192.

9. Sutherst RW: Global change and human vulnerability to vector-borne diseases. Clin Microbiol Rev 2004, 17:136-173.

10. Brooks DR, Hoberg EP: How will global climate change affect parasitehost assemblages? Trends Parasitol 2007, 23:571-574.

11. Reitz SR, Trumble JT: Competitive displacement among insects and arachnids. Annu Rev Entomol 2002, 47:435-465.

12. Little E, Barrera R, Seto KC, Diuk-Wasser M: Co-occurrence patterns of the dengue vector aedes aegypti and aedes mediovitattus, a dengue competent mosquito in Puerto Rico. Ecohealth 2011, 8:365-375.

13. Kweka EJ, Zhou G, Beilhe LB, Dixit A, Afrane Y, Gilbreath TM, Munga S, Nyindo M, Githeko AK, Yan G: Effects of co-habitation between anopheles gambiae s.s. And Culex quinquefasciatus aquatic stages on life history traits. Parasit Vectors 2012, 5:33

14. Guisan A, Thuiller W: Predicting species distribution: offering more than simple habitat models. Ecol Lett 2005, 8:993-1009.

15. Zimmermann NE Jr, Edwards TC, Graham CH, Pearman PB, Svenning JC: New trends in species distribution modelling. Ecography 2010, 33:985-989.

16. Peterson AT: Ecologic niche modeling and spatial patterns of disease transmission. Emerg Infecti Dis 2006, 12:1822-1826.

17. Quante M: The changing climate: past, present, future. In Relict species: Phylogeography and Conservation biology. Edited by Habel JC, Assmann T. Berlin: Springer; 2010:9-56.

18. Liu X, Guo Z, Ke Z, Wang S, Li Y: Increasing potential risk of a global aquatic invader in Europe in contrast to other continents under future climate change. PLoS One 2011, 6:e18429.

19. Caminade C, Medlock JM, Ducheyne E, Mclntyre KM, Leach S, Baylis M, Morse AP: Suitability of European climate for the Asian tiger mosquito Aedes albopictus: recent trends and future scenarios. J $R$ Soc Interface 2013, 9:2708-2717

20. Brownstein JS, Holford TR, Fish D: Effect of climate change on Lyme disease risk in North America. Eco Health 2005, 2:38-46.

21. Peterson AT: Shifting suitability for malaria vectors across Africa with warming climates. BMC Infect Dis 2009, 9:59.

22. Gonzàlez C, Wang O, Strutz SE, Gonzàlez-Salazar C, Sànchez-Cordero V, Sarkar S: Climate change and risk of leishmaniasis in North America: predictions from ecological niche models of vector and reservoir species. PLoS Negl Trop Dis 2010, 4:e585.

23. Larson SR, De Groote JP, Bartholomay LC, Sugumaran R: Ecological niche modeling of potential West Nile virus vector mosquito species in lowa. J Insect Sci 2010, 10:110.

24. Rose $H$, Wall R: Modelling the impact of climate change on spatial patterns of disease risk: sheep blowfly strike by Lucilia sericata in Great Britain. Int J Parasitol 2011, 41:739-746.

25. Illoldi-Rangel P, Rivaldi CL, Sissel B, Trout Fryxell R, Gordillo-Pérez G, Rodríguez-Moreno A, Williamson P, Montiel-Parra G, Sánchez-Cordero V, Sarkar S: Species distribution models and ecological suitability analysis for potential tick vectors of lyme disease in mexico. J Trop Med 2012. doi:10.1155/2012/959101 
26. Parola P, Raoult D: Tick-borne bacterial diseases emerging in Europe. Clin Microbiol Infect 2001, 7:80-83.

27. Stojek NM, Dutkiewicz J: Studies on the occurrence of gram negative bacteria in ticks: ixodes ricinus as a potential vector of pasturella. Ann Agric Environ Med 2004, 11:319-22.

28. Süss J, Klaus C, Diller R, Schrader C, Wohanka N, Abel U: TBE incidence versus virus prevalence and increased prevalence of the TBE virus in ixodes ricinus removed from humans. Int J Med Microbiol 2006, 296:63-68.

29. Eremeeva ME, Oliveira A, Moriarity J, Robinson JB, Tokarevich NK, Antyukova LP, Pyanyh VA, Emeljanova ON, Ignatjeva VN, Buzinov R, Pyankova V, Dasch GA: Detection and identification of bacterial agents in Ixodes persulcatus Schulze ticks from the north western region of Russia. Vector Borne Zoonotic Dis 2007, 7:426-436

30. Jääskeläinen $A E$, Tonteri $E$, Sironen $T$, Pakarinen L, Vaheri $A$, Vapalahti $O$ : European subtype tick-borne encephalitis virus in ixodes persulcatus ticks. Emerg Infect Dis 2011, 17:323-325.

31. Dantas-Torres F, Chomel BB, Otranto D: Ticks and tick-borne diseases: a one health perspective. Trends Parasitol 2012, 28:437-446.

32. Gray JS: The development and seasonal activity of the tick ixodes ricinus, a vector of Lyme borreliosis. Rev Med Vet Entomol 1991, 79:323-339.

33. Korenberg El, Gorban' LY, Kovalevskii YV, Frizen VI, Karavanov AS: Risk for human tick-borne encephalitis, borrelioses, and double infection in the pre-ural region of Russia. Emerg Infect Dis 2001, 7:459-462.

34. Bugmyrin SV, Bespyatova LA, Korotkov YS, Burenkova LA, Belova OA, Romanova LI, Kozlovskaya LI, Karganova GG, leshko EP: Distribution of ixodes ricinus and 1. Persulcatus ticks in southern Karelia (Russia). Ticks Tick Borne Dis 2013, 4:57-62.

35. Lindgren $\mathrm{E}$, Tälleklint $\mathrm{L}$, Polfeldt T: Impact of climatic change on the northern distribution limit and population density of the diseasetransmitting European tick ixodes ricinus. Environ Health Perspect 2000, 108:119-123.

36. Materna J, Daniel M, Danielová V: Altitudinal distribution limit of the tick Ixodes ricinus shifted considerably towards higher altitudes in central Europe: results of three years monitoring in the Krkonose Mts. (Czech Republic). Cent Eur J Publ Health 2005, 13:24-28.

37. Cadenas FM, Rais O, Jouda F, Douet V, Humair PF, Moret J, Gern L: Phenology of Ixodes ricinus and infection with Borrelia burgdorferi sensu lato along a north- and south-facing altitudinal gradient on Chaumont Mountain, Switzerland. J Med Entomol 2007, 44:683-693.

38. Lindgren $\mathrm{E}$, Jaenson TGT: Lyme borreliosis in Europe: influences of climate and climate change, epidemiology, ecology and adaptation measures. Copenhagen, Denmark: WHO Regional Office for Europe; 2006.

39. Jore $S$, Viljugrein $H$, Hofshagen $M$, Brun-Hansen $H$, Kristoffersen $A B$, Nygard K, Brun E, Ottesen P, Saevik BK, Ytrehus B: Multi-source analysis reveals latitudinal and altitudinal shifts in range of Ixodes ricinus at its northern distribution limit. Parasit Vectors 2011, 4:84.

40. Jaenson TGT, Jaenson DGE, Eisen L, Petersson E, Lindgren E: Changes in the geographical distribution and abundance of the tick Ixodes ricinus during the past 30 years in Sweden. Parasit Vectors 2012, 5:8.

41. IPCC: Climate change 2007: the physical science basis. In Contribution of working group I to the fourth assessment report of the intergovernmental panel on climate change. Edited by Solomon S, Qin D, Manning M, Chen Z Marquis M, Averyt KB, Tignor M, Miller HL. United Kingdom and New York: Cambridge University Press, Cambridge; 2007.

42. Phillips SJ, Anderson RP, Schapire RE: Maximum entropy modeling of species geographic distributions. Ecol Model 2006, 190:231-259.

43. Elith J, Graham CH, Anderson RP, Dudik M, Ferrier S, Guisan A, Hijmans RJ, Huettmann F, John R: Novel methods improve prediction of species' distributions form occurrence data. Ecography 2006, 29:129-151.

44. Elith J, Phillips SJ, Hastie T, Dudik M, En Chee Y, Yates CJ: A statistical explanation of MaxEnt for ecologists. Diversity Distrib 2011, 17:43-57.

45. Wisz MS, Hijmans RJ, Peterson AT, Graham CH, Guisan A, NCEAS Predicting Species Distributions Working Group: Effects of sample size on the performance of species distribution models. Divers Distrib 2008, 14:763-773.

46. Oppel S, Meirinho A, Ramírez I, Gardner B, O'Connell AF, Miller PI, Louzao M: Comparison of five modelling techniques to predict the spatial distribution and abundance of seabirds. Biol Conserv 2012, 156:94-104.

47. Estrada-Peña A, Farkas R, Jaenson TG, Koenen F, Madder M, Pascucci I, Salman M, Tarres-Call J, Jongejan F: Association of environmental traits with the geographic ranges of ticks (acari: ixodidae) of medical and veterinary importance in the western palearctic: a digital data set. Exp Appl Acarol 2013, 59:351-366
48. Warren DL, Seifert SN: Ecological niche modeling in maxent: the importance of model complexity and the performance of model selection criteria. Ecol App/ 2011, 21:335-342.

49. Peterson AT, Papeş M, Eaton M: Transferability and model evaluation in ecological niche modeling: a comparison of GARP and maxent. Ecography 2007, 30:550-560.

50. Phillips SJ, Dudik M: Modelling of species distributions with maxent: new extensions and a comprehensive evaluation. Ecography 2008, 31:161-175.

51. Nakicenovic N, Swart R: Emissions scenarios. United Kingdom, Cambridge: University Press., Cambridge; 2000.

52. Scinocca JF, Mcfarlane NA, Lazare M, Li J, Plummer D: Technical note: the CCCma third generation AGCM and its extension into the middle atmosphere. Atmos Chem Phys 2008, 8:7055-7074.

53. Pearson RG: Species' distribution modeling for conservation educators and practitioners. Synthesis. New York Am Mus Natl Hist; 2007. http://ncep.amnh.org.

54. Gern L, Jaulhac B: Life cycle of Borrelia burgdorferi sensu lato and trasmission to humans. In Lyme borreliosis. Current problem in dermatology. Edited by Lipsker D. Switzerland: Karger (Basel); 2009:19-30.

55. Estrada-Peña A, Ayllón N, de la Fuente J: Impact of climate trends on tick-borne pathogen transmission. Front Physiol 2012, 3:1-12.

56. Andreassen $A$, Jore $S$, Cuber $P$, Dudman $S$, Tengs $T$, Isaksen $K$, Hygen $H O$ Viljugrein $\mathrm{H}$, Ånestad G, Ottesen P, Vainio K: Prevalence of tick borne encephalitis virus in tick nymphs in relation to climatic factors on the southern coast of Norway. Parasit Vectors 2012, 5:177.

57. Soberon JM, Peterson AT: Interpretation of models of fundamental ecological niches and species' distributional areas. Biodiv Inform 2005, 2:1-10.

58. Medlock JM, Hansford KM, Bormane A, Derdakova M, Estrada-Peña A, George JC, Golovljova I, Jaenson TG, Jensen JK, Jensen PM: Driving forces for changes in geographical distribution of Ixodes ricinus ticks in Europe. Parasit Vectors 2013, 6:1.

59. Filippova NA: Forms of sympatry and possible ways of microevolution of closely related species of the group Ixodes ricinus-persulcatus (Ixodidae). Acta Zool Lit 2002, 12:1392-1657.

60. Swanson SJ, Neitzel D, Reed KD, Belongia EA: Coinfections acquired from Ixodes Ticks. Clin Microbiol Rev 2006, 19:708-727.

61. Araújo MB, Luoto M: The importance of biotic interactions for modelling species distributions under climate change. Glob Ecol Biogeogr 2007, 16:743-753.

62. Fischer D, Moeller P, Thomas SM, Naucke TJ, Beierkuhnlein C: Combining climatic projections and dispersal ability: a method for estimating the responses of sandfly vector species to climate change. PLOS Negl Trop Dis 2011, 5:e1407.

63. Sonenshine DE: Biology of ticks, Volume 1. New York: Oxford University Press; 1991.

64. Sonenshine DE: Biology of ticks, Volume 2. New York: Oxford University Press; 1993.

65. Milne A: The ecology of the sheep tick, Ixodes ricinus-host relationships of the tick part 1: review of previous work in Britain. Parasitology 1949, 39:167-172.

66. Poulin R, Keeney DB: Host specificity under molecular and experimental scrutiny. Trends Parasitol 2008, 24:24-28

67. Porretta D, Mastrantonio V, Mona S, Epis S, Montagna M, Sassera D, Bandi C, Urbanelli S: The integration of multiple independent data reveals an unusual response to Pleistocene climatic changes in the hard tick Ixodes ricinus. Mol Eco 2013, 22(6):1666-82.

68. Korch GW: Geographic dissemination of tick-borne zoonoses. New York: Oxford University Press; 1994

69. Estrada-Peña A: The relationships between habitat topology, critical scales of connectivity and tick abundance Ixodes ricinus in a heterogeneous landscape in northern Spain. Ecography 2003, 26:661-671.

70. Estrada-Peña A: Climate, niche, ticks, and models: what they are and how we should interpret them. Parasitol Res 2008, 103(Suppl. 1):S87-S95.

71. Santos-Silva MM, Sousa R, Santos AS, Melo P, Encarnação V, Bacellar F: Ticks parasitizing wild birds in Portugal: detection of Rickettsia aeschlimannii, R. helveticaand, R. massiliae. Exp Appl Acarol 2006, 39:331-338.

72. Hasle G, Bjune G, Edvardsen E, Jakobsen C, Linnehol B, Røer JE, Mehl R, Røed KH, Pedersen J, Leinaas HP: Transport of ticks by migratory passerine birds to Norway. J Parasitol 2009, 95:1342-1351.

73. De Meeûs T, Beati L, Delaye C, Aeschlimann A, Renaud F: Sex-biased genetic structure in the vector of Lyme disease, Ixodes ricinus. Evolution 2002, 56:1802-1807. 
74. Paulauskas A, Radzijevskaja J, Rosef O, Turcinaviciene J, Ambrasiene D, Makareviciute D: Genetic variation of ticks (Ixodes ricinus L.) in the Lithuanian and Norwegian populations. Exp Appl Acarol 2006, 40:259-270.

75. Hoogstraal H, Kaiser MN, Traylor MA, Guindy E, Gaber S: Ticks (Ixodidae) on birds migrating from Europe and Asia to Africa, 1959-61. Bull WId Hlth Org 1963, 28:235-262.

76. Hoogstraal H, Traylor MA, Gaber S, Malakatis G, Guindy E, Helmy I: Ticks (ixodidae) on migrating birds in Egypt, spring and fall 1962. Bull Wld Hlth Org 1964, 30:355-367.

77. Ogden NH, Bigras-Poulin M, O'Callaghan CJ, Barker IK, Lindsay LR, Maarouf A, Smoyer-Tomic KE, Waltner-Toews D, Charron D: A dynamic population model to investigate effects of climate on geographic range and seasonality of the tick Ixodes scapularis. Int J Parasitol 2005, 35:375-389.

78. Bostrom A, O'Connor R, Böhm G, Hanss D, Bodi O, Ekström F, Halder P, Jeschke S, Mack B, Qu M, Rosentrater L, Sandve A, Sælensminde I: Causal thinking and support for climate change policies: international survey findings. Glob Environ Chang 2012, 22:210-222.

79. Mastrantonio V, Amendolia S, Porretta D, Gaiarsa S, Epis S, Genchi C, Bandi C, Otranto D, Urbanelli S: Expansion of the climatic niche in the Eurasian tick Ixodes ricinus and I. persulcatus under future climatic changes, Annual meeting of the Italian society of ecology, $16^{\text {th }}-19^{\text {th }}$ September 2013 . Ancona, Italy.

80. Masuzawa T: Terrestrial distribution of the Lyme borreliosis agent borrelia burgdorferi sensu lato in east Asia. Jpn J Infect Dis 2004, 57:229-235.

81. Gray JS, Dautel H, Estrada-Peña A, Kahl O, Lindgren E, Gray JS, Dautel H, Estrada-Peña A, Kahl O, Lindgren E: Effects of climate change on ticks and tick-borne diseases in Europe. Interdiscip Perspect Infect Dis 2009, 2009:593232.

82. Gray JS: Ixodes ricinus seasonal activity: implications of global warming indicated by revisiting tick and weather data. Int J Med Microbiol 2008, 298:19-24.

83. Dautel H, Dippel C, Kämmer D, Werkhausen A, Kah O: Winter activity of ixodes ricinus in a Berlin forest. Int J Med Microbiol 2008, 298:50-54.

84. Dantas-Torres F, Otranto D: Seasonal dynamics of ixodes ricinus on ground level and higher vegetation in a preserved wooded area in southern Europe. Vet Parasitol 2013, 192:253-258.

85. Gern L, Rais O: Efficient transmission of borrelia burgdorferi between cofeeding ixodes ricinus ticks (acari: ixodidae). J Med Entomol 1996, 33:189-92.

doi:10.1186/1756-3305-6-271

Cite this article as: Porretta et al.: Effects of global changes on the climatic niche of the tick Ixodes ricinus inferred by species distribution modelling. Parasites \& Vectors 2013 6:271.

\section{Submit your next manuscript to BioMed Central and take full advantage of:}

- Convenient online submission

- Thorough peer review

- No space constraints or color figure charges

- Immediate publication on acceptance

- Inclusion in PubMed, CAS, Scopus and Google Scholar

- Research which is freely available for redistribution 